\title{
Stress impairs optimal behavior in a water foraging choice task in rats
}

\author{
Lauren K. Graham, ${ }^{1}$ Taejib Yoon, ${ }^{1}$ and Jeansok J. Kim ${ }^{1,2,3}$ \\ ${ }^{1}$ Department of Psychology, University of Washington, Seattle, Washington 98195-1525, USA; ${ }^{2}$ Program in Neurobiology \& \\ Behavior, University of Washington, Seattle, Washington 98195-1525, USA
}

\begin{abstract}
Stress is a biologically significant social-environmental factor that plays a pervasive role in influencing human and animal behaviors. While stress effects on various types of memory are well characterized, its effects on other cognitive functions are relatively unknown. Here, we investigated the effects of acute, uncontrollable stress on subsequent decision-making performance in rats, using a computer vision-based water foraging choice task. Experiencing stress significantly impaired the animals' ability to progressively bias (but not maintain) their responses toward the larger reward when transitioning from equal to unequal reward quantities. Temporary inactivation of the amygdala during stress, however, blocked impairing effects on decision making.
\end{abstract}

[Supplemental material is available online at http://www.learnmem.org.]

It is now well documented that exposure to uncontrollable stress can produce alterations in multiple brain-memory systems in humans and animals (McEwen and Sapolsky 1995; Kim and Diamond 2002; Joels et al. 2006; Shors 2006; Luethi et al. 2008). In humans, impairments in long-term, but not short-term, verbal recall tasks have been observed in people with post-traumatic stress disorder (PTSD) (Bremner et al. 1995) or Cushing's disease (a hypercortisolemia condition) (Starkman et al. 1992) and in healthy individuals subjected to stress (Lupien et al. 1997) or exposed to stress levels of cortisol (Newcomer et al. 1994). In rodents, stress and corticosterone administration interfere with spatial and working memory (Diamond and Rose 1994; de Quervain et al. 1998; Kim et al. 2001) and potentiate aversive conditioning (Shors et al. 1992; Maier et al. 1995). Further, a number of stressassociated neurobiological changes have been identified (e.g., in hippocampus, medial prefrontal cortex, and amygdala) subserving different memory functions (Arnsten and Goldman-Rakic 1998; Kim and Yoon 1998; Vyas et al. 2003; Holmes and Wellman 2009).

Although stress effects on memory have been well studied, far less is known about whether (and in what manner) stress influences other higher cognitive functions. The present study investigated the effects of acute, uncontrollable stress (60-min restraint +60 intermittent tailshocks) on subsequent decisionmaking performance in rats. The stress procedure, in which animals learn that they can neither escape nor predict an aversive experience, was adapted from earlier studies (e.g., Maier and Seligman 1976; Kim et al. 1996). Decision making was assessed using an automated Figure-8-shaped maze on which rats were motivated to forage for water rewards in two different locations under equal and unequal quantity conditions (Fig. 1). In addition to behavioral stress, we examined the effects of corticosterone administration and inactivation of the amygdala during stress on decision making. Both corticosterone (a glucocorticoid hormone released in response to stress) and the amygdala (a structure crucial in defensive behavior) have been implicated in mediating neurocognitive effects of stress (McEwen and Sapolsky 1995; Kim and Diamond 2002).

\footnotetext{
${ }^{3}$ Corresponding author.
}

E-mail jeansokk@u.washington.edu; fax (206) 685-3157.

Article is online at http://www.learnmem.org/cgi/doi/10.1101/lm.1605510.
Experimentally naïve male Charles River Sprague-Dawley rats (initially weighing 275-300 gm) were singly housed and maintained on a reverse 12-h light-dark cycle (lights on at 19:00 h). After $7 \mathrm{~d}$ of acclimation and for the duration of the experiment, daily water access was restricted to maintain approximately $85 \%$ of the animal's normal body weight. Food was available ad libitum throughout the experiment. All experiments were conducted during the dark phase of the cycle and in strict compliance with the University of Washington Institutional Animal Care and Use Committee guidelines. Under anesthesia $(30 \mathrm{mg} / \mathrm{kg}$ ketamine and $2.5 \mathrm{mg} / \mathrm{kg}$ xylazine, i.p.) amygdala (AMYG) animals were chronically implanted with 26-gauge guide cannulae (Plastics One) bilaterally into the amygdala (from bregma: anteroposterior, $-2.3 \mathrm{~mm}$; mediolateral, $\pm 5 \mathrm{~mm}$; dorsoventral, -7.7 to $8.0 \mathrm{~mm}$ ). During $10-15$ d of postoperative recovery, each dummy cannula was removed and replaced with a clean one.

Muscimol free base (Sigma-Aldrich), dissolved in artificial cerebrospinal fluid ( $10 \mathrm{mM}$ at $\mathrm{pH} \sim 7.4)$, was microinfused into the amygdala (bilaterally) via 33-gauge infusion cannulae that protruded $1 \mathrm{~mm}$ beyond the guide cannulae (cf. Kim et al. 2005). An infusion volume of $0.3 \mu \mathrm{L}$ (per side) was delivered using a Harvard PHD2000 syringe pump (Harvard Apparatus) over the course of $3 \mathrm{~min}$. Animals were returned to their home cages for $30 \mathrm{~min}$ before undergoing the stress procedure. We based the timing of inactivation on previous findings that pre-stress but not immediate post-stress inactivation of the amygdala interferes with stress effects on hippocampal long-term potentiation (LTP) and spatial memory (Kim et al. 2005). Based on studies that examined ${ }^{3} \mathrm{H}$-muscimol spreading (Krupa et al. 1993; Arikan et al. 2002) in the cerebellum, in which $1 \mu \mathrm{L}$ diffused a radius of $1.6-2.0 \mathrm{~mm}$, it was estimated that $0.3 \mu \mathrm{L}$ of muscimol would spread within a radius of approximately $0.5-0.7 \mathrm{~mm}$ from the infusion needle tip. Hence, it is likely that infused muscimol would have diffused to the central, lateral, and basal nuclei of the amygdala and possibly to portions of adjacent neighboring structures. The BODIPY TMR-X muscimol conjugate (Invitrogen) was infused in the same manner as muscimol free base (cf. Allen et al. 2008) to image the spread of reversible amygdalar inactivation.

Corticosterone (CORT) animals received three daily subcutaneous injections of $3 \mathrm{mg} / \mathrm{kg}$ corticosterone (suspended in sesame oil; Sigma-Aldrich) $30 \mathrm{~min}$ prior to bias testing. 


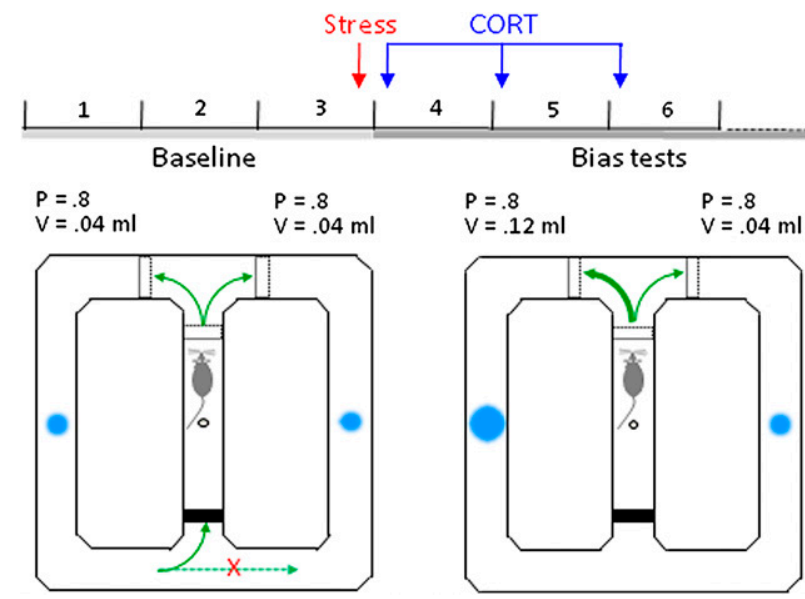

Figure 1. Decision-making task. Thirst-motivated rats were trained to forage for water on an automated Figure-8-shaped maze. A computer algorithm controlled the raising and lowering of four gates (represented by rectangles), the delivery of water (blue circles), and tracking of the animal's location on the maze. During the baseline days, both left and right sides of the maze presented $0.04 \mathrm{~mL}$ of water at $80 \%$ probability (equal reward trials). Following each trial (a left or right loop), the animal returned to the center bridge to start the next trial ( 40 trials per day). During the bias test days, one side of the maze (counterbalanced) offered $0.12 \mathrm{~mL}$ of water at $80 \%$ probability, while the other side continued to present $0.04 \mathrm{~mL}$ of water at $80 \%$ probability (unequal reward trials). Animals received either stress, CORT injections, or neither (for group details, see text).

Rats undergoing stress were restrained in Plexiglas tubes and presented with 60 tailshocks (1-mA intensity, 1-sec duration, 5- to 115 -sec variable intershock interval) for $60 \mathrm{~min}$ (Kim et al. 2005). Animals were divided into four groups: control, stress, amygdalar inactivation plus stress (AMYG), and daily corticosterone (CORT).

Following $2 \mathrm{~d}$ of habituation (to transport, maze, and room ambiance), all animals underwent successive shaping and testing phases. The dimensions and automatic features of the Figure- 8 maze have been described previously (Pedigo et al. 2006; Yoon et al. 2008); for details, see Supplemental material. During shaping, each rat is placed into the center runway with all four gates in the up position (Supplemental Fig. S1). After $3 \mathrm{sec}$, the front and one of the side gates drop, until the rat on its own volition moves out of the center and onto the open side runway. At this point, the lowered front and side gates rise (to prevent the rat from going backward), water is delivered to both the open arm and the center spout, and the back gate drops. The rat consumes water from the open arm, and a new trial begins when he returns to and consumes water from the center arm. There was a 3-sec delay between each trial. During shaping, left and right choices were thus forced choices and were presented in a pseudorandom pattern, such that there was an equal number of both in a complete session (40 laps). Rats underwent shaping once daily until they met predetermined criteria: completion of 40 laps in less than $30 \mathrm{~min}$, and less than five back edge errors (i.e., after making a choice, running up the opposite arm instead of going back to the center arm). The automated program controlled the gates and water delivery, according to the rat's position on the maze.

During baseline testing (Supplemental Fig. S2), the rewards dispensed on left and right arms were equal in both volume $(0.04 \mathrm{~mL})$ and probability $(0.8)$. Each rat remained on baseline testing until he demonstrated a stable left/right choice pattern across three consecutive days. If a slight preference to one side was present, the opposite arm would be the increased reward side when bias testing commenced.

Stress and AMYG rats were exposed to restraint + tailshock stress $1 \mathrm{~d}$ before their first bias test, and CORT rats were given corticosterone injections $30 \mathrm{~min}$ prior to each bias test. During bias testing (Supplemental Fig. S3), the reward value on one side was tripled in volume $(0.12 \mathrm{~mL})$ while the value for the other side remained constant $(0.04 \mathrm{~mL})$. Control, AMYG, and CORT animals were given three consecutive days of bias tests, while stress animals underwent six consecutive days of bias tests.

At the completion of behavioral testing, animals were overdosed with urethane and perfused intracardially with $0.9 \%$ saline followed by $10 \%$ buffered formalin. The brains were removed and stored in 10\% formalin overnight and then kept in 30\% sucrose solution until they sank. Transverse sections $(50 \mu \mathrm{m})$ were taken through the extent of the cannulae tract, mounted on gelatincoated slides, and stained with cresyl violet to verify cannulae placements.

The visit number to the left (or right) side of the maze for baseline and bias days were normalized to the mean left (or right) visits across the three baseline days. Statistical comparisons between groups were examined using ANOVA. For a significant difference $(P<0.05)$, post-hoc comparisons were performed using Tukey's honestly significant difference test.

Thirst-motivated rats readily learned to forage for water on the maze, and when left and right sides of the maze provided the same quantity $(0.04 \mathrm{~mL})$ and probability $(80 \%)$ of water, the animals made comparable numbers of left and right visits (during 40 laps daily) that were stable across three baseline days (Fig. 2A). The $80 \%$ probability (a partial reinforcement schedule) was used so that animals frequently explored both sides of the maze. After animals demonstrated stable baseline choices, the volume of water on one side was tripled $(0.12 \mathrm{~mL}$ at $80 \%)$, while the other side remained constant $(0.04 \mathrm{~mL}$ at $80 \%)$. Overall, bias performance (choice of the larger reward) increased across the first three bias test days (repeated-measures ANOVA; main effect of day, $F_{(2,54)}=$ $78.16, P<0.001)$. However, the four groups differentially increased their bias across days (group $\times$ day interaction, $F_{(6,54)}=4.14$,
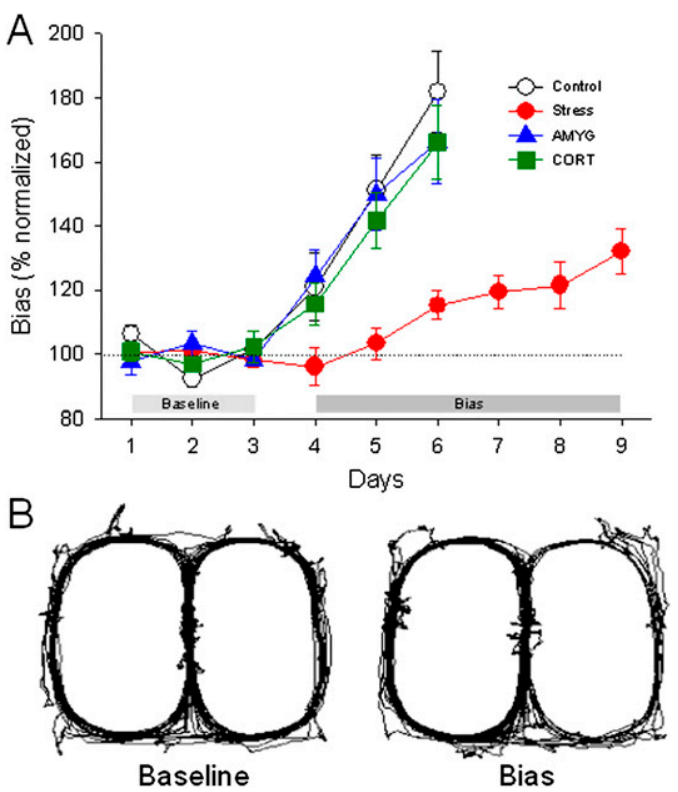

Figure 2. Stress effects on decision making. (A) All groups of animals showed comparable visits to left and right sides of the maze during the three baseline days. When transitioning from equal to unequal reward trials, stressed rats $(n=7)$ displayed an impaired ability to bias their responses toward the larger reward side compared with control $(n=10)$, AMYG $(n=7)$, and CORT $(n=7)$ rats $(P=0.002$, group $\times$ bias day interaction). (B) Example visit maps of a control rat during baseline and bias days (40 laps each). 
$P<0.01)$. Specifically, stressed rats displayed a significantly slower rate of bias toward the larger reward than did the controls $(P<$ 0.01 , Tukey). The stressed rats did ultimately develop a bias compared with their baseline choices $\left(F_{(6,62)}=8.44, P<0.001\right)$. This bias was first significant on the fourth day $(P<0.05$, Dunnett $t$-test). However, even after $6 \mathrm{~d}$ of bias testing, their bias (127 \pm $5.7 \%$, mean \pm SEM) did not reach the level of controls' third day bias $(182 \pm 12.2 \%)$. Unlike the behavioral stress group, however, animals that received three daily corticosterone injections $(3 \mathrm{mg} / \mathrm{kg}$, subcutaneously) prior to testing chose the larger reward side more frequently (173 $\pm 6.7 \%$, bias day 3$)$ and did not differ from the control group $(P>0.7$, Tukey). When the amygdalae were inactivated during stress (Fig. 3), these animals behaved like controls $(P>0.7$, Tukey) and increased their visit frequency toward
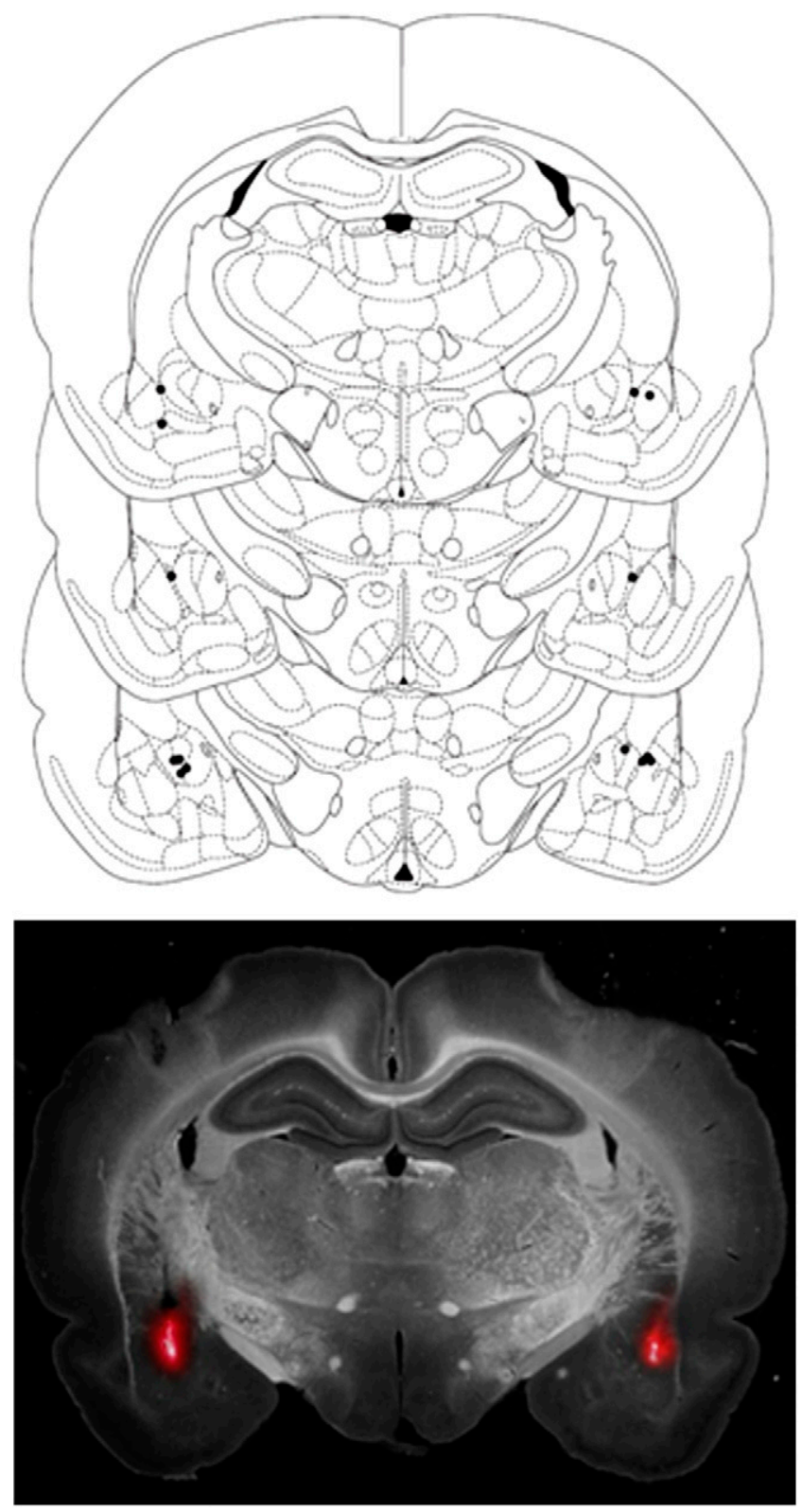

Figure 3. (Top) Histological reconstruction of injection cannulae placement tips in the amygdala. (Bottom) A photomicrograph of fluorophoreconjugated muscimol ( $0.3 \mu \mathrm{L}$ over $3 \mathrm{~min})$ spread in the amygdala. The red fluorescence is overlaid with a dark field image. the larger reward side of the maze $(174 \pm 13.0 \%$, bias day 3$)$ (Fig. 2A). Although control, CORT, and AMYG animals developed strong bias responses, they did not exclusively visit the larger reward side of the maze because on $20 \%$ of trials they did not receive a reward.

We then examined whether stress might have produced alterations in motor, motivation, and reference memory performances that hindered the animals' ability to bias their responses toward the larger reward. The latency to complete 40 laps of the first bias test session (Supplemental Fig. S4A) showed a trend of stress animals completing the bias test faster than the other three groups, but this group $\times$ day interaction was not significant $\left(F_{(6,54)}=1.89, P>0.05\right)$. Stress also did not impair the animals' reference memory of the maze (Supplemental Fig. S4B). That is, after making a left or right visit, stressed animals readily re-entered the center runway to start the next trial (one-way ANOVA; average baseline and first three bias days, $\left.F_{(3,41)}=0.20, P>0.8\right)$, whereas control, CORT, and AMYG animals displayed an increased propensity to investigate the other side before re-entering the center, particularly as bias testing progressed (repeated-measures ANOVA; main effect of day, $\left.F_{(2,54)}=4.84, P<0.05\right)$.

Our results indicate that rats clearly demonstrate the capacity to change their foraging behavior to acquire a larger water reward when transitioning from equal to unequal quantities, and that such behavioral flexibility is vulnerable to acute, uncontrollable stress. Specifically, rats that experienced $1 \mathrm{~h}$ of restraint stress +60 intermittent tailshocks were significantly impaired in biasing their responses toward the side of the maze with a larger quantity of water. This effect on bias was not due to any lingering post-stress motivational or motor effects, as stress did not increase the latency to complete the bias test. Daily corticosterone injections did not interfere with this task, indicating that corticosterone elevation per se cannot reproduce behavioral stress effects on behavioral flexibility. However, similar to previous stress-memory studies (Kim et al. 2001; Waddell et al. 2008), amygdalar inactivation during stress effectively blocked this effect. This suggests that the amygdala plays a crucial role in mediating stress effects across different cognitive domains.

Although stress altered the rats' behavior in our choice-based task, it remains unclear precisely which neural and cognitive systems were affected. For instance, the impairment of behavioral flexibility might be an indirect consequence of stress effects on hippocampal memory functioning. The stress paradigm used here is known to impede LTP in the CA1 hippocampus and hinder spatial memory (Foy et al. 1987; Kim et al. 2001). However, corticosterone, which also impedes LTP (McEwen and Sapolsky 1995) and spatial memory when administered 30 min before testing (de Quervain et al. 1998), did not impair behavioral flexibility. The impairment to choose the larger reward may be due to stress effects on working memory, such that the rats cannot remember (and thus learn) that one reward is larger. However, if true, the stressinduced memory impairment is unusually persistent in our task: Rats were affected through at least $6 \mathrm{~d}$ beyond the stress exposure. Because acquisition and retrieval of information are integral components of decision making, the contribution of stress-associated changes in learning and memory cannot be fully excluded. Another possibility is that stressed rats are more likely to use habitual rather than flexible strategies, even when a change in behavior may be optimal. Consistent with this explanation are recent findings that chronic stress exposure increases habit-based responding, with corresponding atrophy and hypertrophy of goaldirected and habit-based neural circuitry, respectively (DiasFerreira et al. 2009). The reliance on habit memory is also increased following anxiogenic drug infusions into the amygdala (Elliott and Packard 2008), which further implicates amygdalar modulatory activity during and after stress exposure in decreasing flexible 
behavior. If the stress experience did increase perseverative choice behavior, this may partially explain previously observed associations between distress and perseveration in humans (Robinson et al. 2006). Alternately, stress may have disrupted the reward circuitry and impaired the ability to discriminate between the two reward values from the two side arms, in which case stress effects on a dopamine-related reward circuit (Schultz et al. 1997) should be explored. However, this cannot be the sole explanation because post-bias stress did not affect the animals' bias behavior toward the larger reward (Supplemental Table S1), and nonstressed rats resume equal arm visits when rewards are returned to baseline values (data not shown).

The present findings reveal that a single exposure to an acutely stressful experience is enough to affect an animal's behavior on a simple forging task for several days. There is accumulating evidence that exposure to stress increases amygdala and decreases prefrontal activity in both humans and animals (for review, see Arnsten 2009) and that even a single stress exposure alters cellular morphology in prefrontal cortex (Izquierdo et al. 2006). This shift in neural activity may promote the use of one cognitive strategy over another (e.g., habitual versus flexible). To address this, future studies need to investigate brain structures implicated in decision making, including the prefrontal and the parietal cortices (Gold and Shadlen 2007; Lee 2008), for their susceptibility to stress. Regardless, the present findings, to our knowledge, provide the first direct evidence that acute uncontrollable stress persistently impairs decision-making performance in animals and that this effect is dependent upon amygdalar activity during stress.

\section{Acknowledgments}

We thank Andrew R. Graham for the Figure-8 maze control and analyses programs, and Valentino C. Garcia and Joseph Reichert for their assistance in the experiment. This work was supported by NIH grant R01 MH64457 and the University of Washington Royalty Research Fellowship (J.J.K). The authors declare no competing financial interests.

\section{References}

Allen TA, Narayanan NS, Kholodar-Smith DB, Zhao Y, Laubach M, Brown TH. 2008. Imaging the spread of reversible brain inactivations using fluorescent muscimol. J Neurosci Methods 171: 30-38.

Arikan R, Blake NM, Erinjeri JP, Woolsey TA, Giraud L, Highstein SM. 2002. A method to measure the effective spread of focally injected muscimol into the central nervous system with electrophysiology and light microscopy. J Neurosci Methods 118: 51-57.

Arnsten AF. 2009. Stress signaling pathways that impair prefrontal cortex structure and function. Nat Rev Neurosci 10: 410-422.

Arnsten AF, Goldman-Rakic PS. 1998. Noise stress impairs prefrontal cortical cognitive function in monkeys: Evidence for a hyperdopaminergic mechanism. Arch Gen Psychiatry 55: 362-368.

Bremner JD, Randall P, Scott TM, Bronen RA, Seibyl JP, Southwick SM, Delany RC, McCarthy G, Charney DS, Innis RB. 1995. MRI-based measurement of hippocampal volume in patients with combat-related posttraumatic stress disorder. Am I Psychiatry 152: 973-981.

de Quervain DJ, Roozendaal B, McGaugh JL. 1998. Stress and glucocorticoids impair retrieval of long-term spatial memory. Nature 394: 787-790.

Diamond DM, Rose GM. 1994. Stress impairs LTP and hippocampaldependent memory. Ann N Y Acad Sci 746: 411-414.

Dias-Ferreira E, Sousa JC, Melo I, Morgado P, Mesquita AR, Cerqueira JJ, Costa RM, Sousa N. 2009. Chronic stress causes frontostriatal reorganization and affects decision-making. Science 325: 621-625.

Elliott AE, Packard MG. 2008. Intra-amygdala anxiogenic drug infusion prior to retrieval biases rats toward the use of habit memory. Neurobiol Learn Mem 90: 616-623.
Foy MR, Stanton ME, Levine S, Thompson RF. 1987. Behavioral stress impairs long-term potentiation in rodent hippocampus. Behav Neural Biol 48: $138-149$.

Gold JI, Shadlen MN. 2007. The neural basis of decision making. Annu Rev Neurosci 30: 535-574.

Holmes A, Wellman CL. 2009. Stress-induced prefrontal reorganization and executive dysfunction in rodents. Neurosci Biobehav Rev 33: 773 783.

Izquierdo A, Wellman CL, Holmes A. 2006. Brief uncontrollable stress causes dendritic retraction in infralimbic cortex and resistance to fear extinction in mice. J Neurosci 26: 5733-5738.

Joels M, Pu Z, Wiegert O, Oitzl MS, Krugers HJ. 2006. Learning under stress: How does it work? Trends Cogn Sci 10: 152-158.

Kim JJ, Diamond DM. 2002. The stressed hippocampus, synaptic plasticity and lost memories. Nat Rev Neurosci 3: 453-462.

Kim JJ, Yoon KS. 1998. Stress: Metaplastic effects in the hippocampus. Trends Neurosci 21: 505-509.

Kim JJ, Foy MR, Thompson RF. 1996. Behavioral stress modifies hippocampal plasticity through $N$-methyl-D-aspartate receptor activation. Proc Natl Acad Sci 93: 4750-4753.

Kim JJ, Lee HJ, Han JS, Packard MG. 2001. Amygdala is critical for stressinduced modulation of hippocampal long-term potentiation and learning. J Neurosci 21: 5222-5228.

Kim JJ, Koo JW, Lee HJ, Han JS. 2005. Amygdalar inactivation blocks stressinduced impairments in hippocampal long-term potentiation and spatial memory. J Neurosci 25: 1532-1539.

Krupa DJ, Thompson JK, Thompson RF. 1993. Localization of a memory trace in the mammalian brain. Science 260: 989-991.

Lee D. 2008. Game theory and neural basis of social decision making. Nat Neurosci 11: 404-409.

Luethi M, Meier B, Sandi C. 2008. Stress effects on working memory, explicit memory, and implicit memory for neutral and emotional stimuli in healthy men. Front Behav Neurosci 2: 1-9.

Lupien SJ, Gaudreau S, Tchiteya BM, Maheu F, Sharma S, Nair NP, Hauger RL, McEwen BS, Meaney MJ. 1997. Stress-induced declarative memory impairment in healthy elderly subjects: Relationship to cortisol reactivity. J Clin Endocrinol Metab 82: 2070-2075.

Maier SF, Seligman MEP. 1976. Learned helplessness: Theory and evidence. J Exp Psychol 105: 3-46.

Maier SF, Busch CR, Maswood S, Grahn RE, Watkins LR. 1995. The dorsal raphe nucleus is a site of action mediating the behavioral effects of the benzodiazepine receptor inverse agonist DMCM. Behav Neurosci 109: 404-412.

McEwen BS, Sapolsky RM. 1995. Stress and cognitive function. Curr Opin Neurobiol 5: 205-216.

Newcomer JW, Craft S, Hershey T, Askins K, Bardgett ME. 1994. Glucocorticoid-induced impairment in declarative memory performance in adult humans. J Neurosci 14: 2047-2053.

Pedigo SF, Song EY, Jung MW, Kim JJ. 2006. A computer vision-based automated Figure-8 maze for working memory test in rodents. J Neurosci Methods 156: 10-16.

Robinson MD, Wilkowski BM, Kirkeby BS, Meier BP. 2006. Stuck in a rut: Perseverative response tendencies and the neuroticism-distress relationship. J Exp Psychol Gen 135: 78-91.

Schultz W, Dayan P, Montague PR. 1997. A neural substrate of prediction and reward. Science 275: 1593-1599.

Shors TJ. 2006. Significant life events and the shape of memories to come: A hypothesis. Neurobiol Learn Mem 85: 103-115.

Shors TJ, Weiss C, Thompson RF. 1992. Stress-induced facilitation of classical conditioning. Science 257: 537-539.

Starkman MN, Gebarski SS, Berent S, Schteingart DE. 1992. Hippocampal formation volume, memory dysfunction, and cortisol levels in patients with Cushing's syndrome. Biol Psychiatry 32: 756-765.

Vyas A, Bernal S, Chattarji S. 2003. Effects of chronic stress on dendritic arborization in the central and extended amygdala. Brain Res 965: 290294.

Waddell J, Bangasser DA, Shors TJ. 2008. The basolateral nucleus of the amygdale is necessary to induce the opposing effects of stressful experience on learning in males and females. J Neurosci 28: 52905294.

Yoon T, Okada J, Jun MW, Kim JJ. 2008. Prefrontal cortex and hippocampus subserve different components of working memory in rats. Learn Mem 15: $97-105$

Received August 24, 2009; accepted in revised form November 5, 2009. 


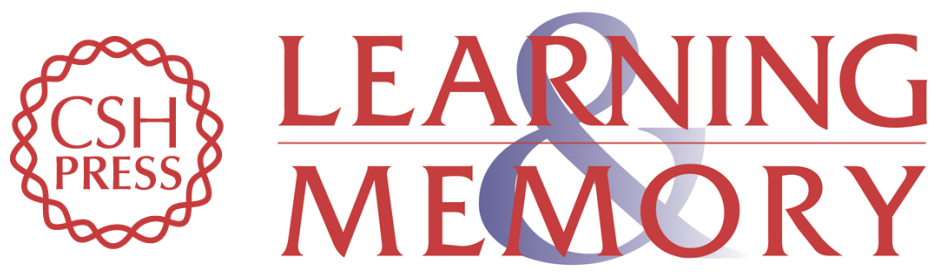

\section{Stress impairs optimal behavior in a water foraging choice task in rats}

Lauren K. Graham, Taejib Yoon and Jeansok J. Kim

Learn. Mem. 2010, 17:

Access the most recent version at doi:10.1101//m.1605510

References This article cites 36 articles, 11 of which can be accessed free at: http://learnmem.cshlp.org/content/17/1/1.full.html\#ref-list-1

License

Email Alerting Receive free email alerts when new articles cite this article - sign up in the box at the Service top right corner of the article or click here. 